\title{
The relationship between the female athlete triad and injury rates in collegiate female athletes
}

\author{
Mutsuaki Edama $^{\text {Corresp., } 1,2}{ }^{,}$Hiromi Inaba ${ }^{1,3}$, Fumi Hoshino $^{3}$, Saya Natsui ${ }^{3}$, Sae Maruyama $^{2}$, Go Omori ${ }^{1,4}$ \\ ${ }^{1}$ Athlete Support Research Center, Niigata University of Health and Welfare, Niigata, Japan, Niigata, Niigata, Japan \\ 2 Institute for Human Movement and Medical Sciences, Niigata University of Health and Welfare, Niigata, Japan, Niigata, Niigata, Japan \\ 3 Department of Health and Nutrition, Niigata University of Health and Welfare, Niigata, Japan, Niigata, Japan \\ 4 Department of Health and Sports, Niigata University of Health and Welfare, Niigata, Japan, Niigata, Niigata, Japan \\ Corresponding Author: Mutsuaki Edama \\ Email address: edama@nuhw.ac.jp
}

Background. This study aimed to clarify the relationship between the triad risk assessment score and the sports injury rate in 116 female college athletes (average age, $19.8 \pm 1.3$ years) in 7 sports at the national level of competition; 67 were teenagers, and 49 were in their 20s. Methods. Those with menstrual deficiency for $>3$ months or $<6$ menses in 12 months were classified as amenorrheic athletes. Low energy availability was defined as adolescent athletes having a body weight $<85 \%$ of ideal body weight, and for adult athletes in their $20 \mathrm{~s}$, a body mass index $\leq 17.5 \mathrm{~kg} / \mathrm{m}^{2}$. Bone mineral density (BMD) was measured on the heel of the right leg using an ultrasonic bone densitometer. Low BMD was defined as a BMD Z-score $<-1.0$. The total score for each athlete was calculated. And the cumulative risk assessment was defined as follows: low risk (a total score of 0-1), moderate risk (2-5), and high risk (6). The injury survey recorded injuries referring to the injury survey items used by the International Olympic Committee. Results. In swimming, significantly more athletes were in the low-risk category than in the moderate and highrisk categories $(p=0.004)$. In long-distance athletics, significantly more athletes were in the moderate-risk category than in the low and high-risk categories $(p=0.004)$. In the moderate and high-risk categories, significantly more athletes were in the injury group, whereas significantly more athletes in the low-risk category were in the non-injury group $(p=0.01)$. Significantly more athletes at moderate and high-risk categories had bone stress fractures and bursitis than athletes at low risk $(p=0.023)$. Discussion. These results suggest that athletes with relative energy deficiency may have an increased injury risk. 
1 The relationship between the female athlete triad and injury rates in collegiate female

2 athletes

3

4 Mutsuaki Edama $^{1,2}$, Hiromi Inaba ${ }^{1,3}$, Fumi Hoshino ${ }^{3}$, Saya Natsui ${ }^{3}$, Sae Maruyama ${ }^{2}$, Go Omori ${ }^{1,4}$ 5

6

$7 \quad{ }^{1}$ Athlete Support Research Center, Niigata University of Health and Welfare

$8 \quad 2$ Institute for Human Movement and Medical Sciences, Niigata University of Health and

9 Welfare

$10{ }^{3}$ Department of Health and Nutrition, Niigata University of Health and Welfare

$11{ }^{4}$ Department of Health and Sports, Niigata University of Health and Welfare

14 Corresponding author: Mutsuaki Edama

Institute for Human Movement and Medical Sciences Niigata University of Health and Welfare 
Abstract

Background. This study aimed to clarify the relationship between the triad risk assessment score and the sports injury rate in 116 female college athletes (average age, $19.8 \pm$ 1.3 years) in 7 sports at the national level of competition; 67 were teenagers, and 49 were in their 20 s.

Methods. Those with menstrual deficiency for $>3$ months or $<6$ menses in 12 months were classified as amenorrheic athletes. Low energy availability was defined as adolescent athletes having a body weight $<85 \%$ of ideal body weight, and for adult athletes in their 20 s, a body mass index $\leq 17.5 \mathrm{~kg} / \mathrm{m}^{2}$. Bone mineral density (BMD) was measured on the heel of the right leg using an ultrasonic bone densitometer. Low BMD was defined as a BMD Z-score $<-1.0$. The total score for each athlete was calculated. And the cumulative risk assessment was defined as follows: low risk (a total score of 0-1), moderate risk (2-5), and high risk (6). The injury survey recorded injuries referring to the injury survey items used by the International Olympic Committee. the moderate and high-risk categories $(\mathrm{p}=0.004)$. In long-distance athletics, significantly more athletes were in the moderate-risk category than in the low and high-risk categories $(\mathrm{p}=0.004)$. In the moderate and high-risk categories, significantly more athletes were in the injury group, whereas significantly more athletes in the low-risk category were in the non-injury group $(\mathrm{p}=0.01)$. Significantly more athletes at moderate and high-risk categories had bone stress fractures and bursitis than athletes at low risk $(\mathrm{p}=0.023)$.

Discussion. These results suggest that athletes with relative energy deficiency may have 
47 an increased injury risk.

48

49 Key words: RED-S; low energy availability; Female Athlete Triad Cumulative Risk

50 Assessment; injury

51 


\section{Introduction}

The female athlete triad (hereafter referred to as triad) has three components: (1) low energy availability (LEA) with or without disordered eating (DE)/eating disordered (ED); (2) menstrual dysfunction; and (3) low bone mineral density (BMD) (De Souza et al. 2014). An IOC consensus group has recently introduced a new umbrella term, that is, 'Relative Energy Deficiency in Sport' (RED-S), to describe the physiological and pathophysiological effects of energy deficiency in male and female athletes (Mountjoy et al. 2014). The authors assert that "RED-S is required to more accurately describe the clinical syndrome originally known as the Female Athlete Triad" that is a "more comprehensive, broader term for the overall syndrome, which includes what has so far been called the 'Female Athlete Triad' (Mountjoy et al. 2014) ." RED-S is based on a relative energy deficit that is reported to affect various factors (Mountjoy et al. 2018). However, RED-S is insufficiently supported by scientific research to warrant adoption at this time. Recently, there have been many studies of bone stress fractures and amenorrhea, but their relationships with the occurrence of sports injury have not been examined (De Souza et al. 2014; Nattiv 2000; Nose-Ogura et al. 2019; Reeder et al. 1996; Takamatsu \& Kitawaki 2016). It was previously reported that the frequency of sports injuries was higher in women than in men, suggesting a relationship between the menstrual cycle and sports injuries (Hewett et al. 2007; Park et al. 2009). Especially for ACL injury, many studies have been reported. Gender differences in the incidence of ACL injury include extrinsic factors (physical and visual perturbations, bracing, and shoe-surface interaction) and intrinsic factors (anatomical, neuromuscular, and biomechanical differences between genders), which may be multifactorial in nature (Hewett et al. 2006). Among the intrinsic factors, the effects of female hormones are also thought to play a role in gender differences in the incidence of ACL injury (Arendt et al. 2002; 
Beynnon et al. 2006; Hewett et al. 2006; Wojtys et al. 2002; Wojtys et al. 1998). It has been suggested that there is a strong relationship between the risk of both RED-S and sports injuries.

The advances in our understanding of risk factors and management of the triad are reflected in evidence based guidelines developed by the Female Athlete Triad Coalition in 2014 to help guide medical decision making for female athletes (De Souza et al. 2014). The resulting Female Athlete Triad Cumulative Risk Assessment includes the following 6 items scored on a scale from 0 to 2: low LEA with or without DE/ED; low body mass index (BMI); delayed menarche; oligomenorrhea or amenorrhea; low BMD; and prior stress fracture (De Souza et al. 2014). The resulting risk assessment score is used to classify an athlete into 1 of 3 categories: low risk (0-1 points), moderate risk (2-5 points), or high risk (6 points) (De Souza et al. 2014). Using risk assessment scores to help manage treatment for athletes is important, especially considering the evidence for adverse health consequences resulting from the triad. For example, a higher number of triad risk factors is associated with an increased risk for bone stress injuries and low BMD (Barrack et al. 2014; Gibbs et al. 2014; Tenforde et al. 2013). Furthermore, for female athletes who have one component of the triad, the risk of developing bone stress fractures is about 3 times higher than that of athletes with no components of the triad; the risk is about 5 times higher for those with two or more components (Mallinson \& De Souza 2014). In addition, collegiate athletes with triad risk factors including oligomenorrhea/amenorrhea or increased risk assessment scores had higher grade bone stress fractures on MRI and longer return to play (Nattiv et al. 2013).

Therefore, this study aimed to clarify the relationship between the triad risk assessment score and the number of sports injuries. The hypothesis of this study was that the moderate and high-risk groups have higher injury rates than the low-risk group on the triad risk assessment 
98

99

100

101

102

104

105

106

107

108

109

110

111

112

113

114

115

116

117

118

119

120

score.

\section{Materials \& methods}

\section{Recruitment}

A total of 116 female college athletes (average age, $19.8 \pm 1.3$ years) were investigated; 67 were teenagers, and 49 were in their 20s. They were involved in 7 sports (swimming, athletics sprint, athletics long-distance, athletics throwing/jumping, soccer, basketball and volleyball). All sports were at the national level of competition. Approval was obtained from the Ethics Committee of The Niigata University of Health and Welfare to carry out this study within its facilities (approval no. 18032). Written, informed consent was obtained from all participants.

\section{Self-report using the questionnaire form}

The examinations were conducted from August 2018 to January 2019. The participants were asked about age at menarche, date of last menstrual period, number of menstrual cycles per 12 months, history of bone stress fracture (site and times), dietary restriction, and present or past history of ED/DE using the questionnaire form. Those with menstrual deficiency for $>3$ months (definition of the Japan Society of Obstetrics and Gynecology) or $<6$ menses in 12 months were classed as amenorrheic athletes (De Souza et al. 2014). Data were collected by physical therapists (M.E.) and nutritionists (H.I. and F.H.).

\section{Anthropometry}

Height $(\mathrm{m})$ and body weight $(\mathrm{kg})$ were measured using a body composition monitor (DC150, TANITA, Tokyo, Japan). BMD was measured on the heel of the right leg using an 
121 ultrasonic bone densitometer (AOS-100SA, Hitachi Aloka Medical, Tokyo, Japan). BMD was

122 calculated as osteo-sonoassessment index (OSI) as follows: OSI = transmission index (TI) $\times$

123 speed of sound $(\mathrm{SOS})^{2}$, calculated as $\operatorname{SOS}(\mathrm{m} / \mathrm{s})=$ heel width $(\mathrm{m}) \times$ ultrasonic wave propagation

124 time ( $\mathrm{sec}$ ). A BMD Z-score of $<-1.0$ in the heel is defined as low BMD (as defined by the Triad

125 coalition in 2014). The LEA is defined as energy intake minus energy expenditure of exercise

126 relative to fat-free mass $(\mathrm{FFM})<30 \mathrm{kcal} / \mathrm{kg}$ of $\mathrm{FFM} / \mathrm{d}$, but it is very difficult to calculate energy

127 balance this way during medical examinations. Therefore, the American College of Sports

128 Medicine defines LEA in adolescent athletes as a body weight $<85 \%$ of ideal body weight (IBW),

129 and for adult athletes in their 20s, a BMI $\leq 17.5 \mathrm{~kg} / \mathrm{m}^{2}$ (De Souza et al. 2014; Nose-Ogura et al.

130 2019). Therefore, these criteria were used in the present study (De Souza et al. 2014a). BMI was

131 calculated as body weight $(\mathrm{kg}) /$ height $\left(\mathrm{m}^{2}\right)$. To calculate IBW, the formula recommended by The

132 Japanese Society for Pediatric Endocrinology was used.

133

The Female Athlete Triad Cumulative Risk Assessment

The Female Athlete Triad Cumulative Risk Assessment was used. The following six

factors were scored: (1) LEA with or without DE /ED; (2) low BMI; (3) delayed menarche; (4)

oligomenorrhea and/or amenorrhea; (5) low BMD; and (6) stress reaction/fractures. With respect

to LEA, athletes who received treatment by a psychiatrist received a score of 2 , those with some

dietary restriction as evidenced by self-report or low/inadequate energy intake on diet logs

140

received a score of 1 , and those with no history received a score of 0 . BMI was scored for

141 athletes over 20 years of age, but IBW was used for teenagers. Athletes with a BMI $\leq 17.5 \mathrm{~kg} / \mathrm{m}^{2}$

142 or IBW $<85 \%$ received a score of 2 , and athletes with a BMI between 17.6 and $18.4 \mathrm{~kg} / \mathrm{m}^{2}$ or

143 IBW $<90 \%$ received a score of 1 . A score of 0 was given to athletes with a BMI $\geq 18.5 \mathrm{~kg} / \mathrm{m}^{2}$ or 
144 IBW $\geq 90 \%$. For delayed menarche, athletes who had their menarche at age $>16$ years received a 145 score of 2, athletes who had their menarche at age 15-16 years received a score of 1 , and those 146 with menarche at under 15 years received a score of 0 . Athletes with amenorrhea ( $>3$ months or $147<6$ menses in 12 months) were scored 2, 6-9 menses in 12 months were scored 1, and

eumenorrheic athletes ( $>9$ menses in 12 months) were scored 0 . For low BMD, athletes with a Zscore $\leq-2$ were scored 2 , and those between -1 and -2 were scored 1 ; a score of 0 was given to those over -1 . For a history of stress fractures, those with a history of 2 or more stress fractures or trabecular bone stress fractures were scored 2, those with only one past stress fracture were scored 1 , and those with no stress fractures were scored 0 . Next, the total score for each athlete was calculated, and the cumulative risk assessment was defined as follows: low risk (a total score of 0-1), moderate risk (a score of 2-5), and high risk (a score of 6) (De Souza et al. 2014).

\section{Number of injuries}

An injury survey during sports activities was conducted for one season from April 2018 to March 2019. The injury survey collected injuries that resulted in failure to participate in practice and competition for more than 24 hours after injury, referring to the injury survey items used by the IOC (Junge et al. 2008). Injured body part location and type of injury diagnosis were recorded. Data were collected by seven physical therapists and a medical doctor on the field and in the hospital. Serious illnesses such as stress fractures were diagnosed by a medical doctor at the hospital using X-rays and MRI.

\section{Statistical analysis}

Pearson's chi-square test was used for comparisons of differences in the number of 
167 injuries by risk categories. Fisher's exact test was used for comparisons of differences in the risk 168 categories for each sport, and to compare differences in injured body part-location and the type 169 of

170 injury diagnosis by risk category. Multiple comparisons were performed using the Ryan nominal 171 level for post hoc testing. Statistical analyses were performed using SPSS (Version 26.0; SPSS 172 Japan Inc., Tokyo, Japan). The level of significance was $\mathrm{P}<.05$.

\section{Results}

175

176

177

178

179

180

\section{Athletes' characteristics}

The sports undertaken by the participants were swimming $(n=11)$, athletics sprint $(n=19)$, athletics long-distance $(n=8)$, athletics throwing/jumping $(n=8)$, soccer $(n=27)$, basketball $(n=26)$, and volleyball $(n=17)$.

\section{The three triad components}

There were 4/116 (3.4\%) athletes with LEA (defined as actual body weight of IBW $<85 \%$ for adolescent athletes and a BMI $\leq 17.5 \mathrm{~kg} / \mathrm{m}^{2}$ for adult athletes), $6 / 116(5.2 \%)$ athletes with amenorrhea ( $>3$ months or $<6$ menses in 12 months), and 0/116 (0.0\%) athletes had low BMD (Z-score $<-1.0)$. No players had all three triad components (Figure 1).

\section{Prevalence in the 7 events for 116 athletes assigned to triad risk categories}

In swimming, there were significantly more in the low-risk category than in the moderate and high-risk categories $(\mathrm{p}=0.007)$. In athletics long-distance, there were significantly more in the moderate-risk category than in the low and high-risk categories $(p=0.007)$ (Table 1$)$. 
190 In each scoring category, there was a high proportion $(41 / 116,35.3 \%)$ with a history of bone

191 stress fracture, particularly in athletics long-distance (7/8, 87.5\%) (Table 2).

192

193

194

195

196

197

\section{Number of injuries by triad risk categories (Table 3)}

Since there was only one participant in the high-risk category, the high and moderaterisk categories were combined for the analysis. The number of injuries was $65(n=41)$ in one year. In the moderate and high-risk categories, there were significantly more in the injury group than in the non-injury group $(\mathrm{p}=0.01)$. In the low-risk category, there were significantly more in the non-injury group than in the injury group $(\mathrm{p}=0.01)$.

\section{Injured body part location and type of injury diagnosis by risk category}

There was no significant difference in the injured body part location $(p=0.713)$. For stress fracture and bursitis, there were significantly more in the moderate and high-risk categories than in the low-risk category at injury diagnosis $(p=0.014)($ Table 4$)$.

\section{Discussion}

This study clarified the relationship between the triad risk assessment score and the oneyear sports injury rate for female college students involved in multiple sports. To the best of our knowledge, there have been no studies of the relationship between the triad risk assessment score and the number of sports injuries.

Regarding the type of injury diagnosis by risk category, bone stress fracture and bursitis were significantly higher in the moderate and high-risk category than in the low-risk category. This result supported the hypothesis of this study. In previous studies, a higher number 
213 of triad risk factors was associated with an increased risk for bone stress injuries and low BMD

214 ((Barrack et al. 2014; Gibbs et al. 2014; Tenforde et al. 2013). Furthermore, for athletes with

215 component of the triad, the risk of developing bone stress fractures was about 3-5 times higher

216 than that of athletes with no components of the triad (Mallinson \& De Souza 2014). Therefore,

217 this study was considered to have supported the results of the previous studies. However, it is

218 necessary to examine bursitis in greater detail in the future.

219 In the present study, there were 4/116 (3.4\%) athletes with LEA with or without DE/ED, $2206 / 116(5.2 \%)$ with amenorrhea, and 0/116 (0.0\%) with low BMD. No athletes had all three triad 221 components. In previous study of elite Japanese athletes, the number of athletes with LEA was

222

223

224

225

226

227

228

229

230

231

232

233

234

235

42/300 (14.0\%), with amenorrhea was 117/300 (39.0\%), and with low BMD was 68/300 (22.7\%).

Seventeen athletes $(5.7 \%)$ had both amenorrhea and LEA, whereas $39(13 \%)$ had both

amenorrhea and low BMD, and two (0.7\%) had low BMD and LEA. Sixteen (5.3\%) had all three components of the triad (Nose-Ogura et al. 2019). In previous study of American collegiate athletes, the number of athletes with LEA was 2/323 (0.6\%), the number with oligomenorrhea or amenorrhea was 64/239 (26.8\%), and the number with low BMD was 19/323 (5.9\%) (Tenforde et al. 2017). The cause for the differences may be related to the differences in competition level and measurement methods.

In swimming, the number in the low-risk category was significantly higher than in the moderate and high-risk categories. In athletics long-distance, the number in the moderate-risk category was significantly higher than in the low-risk category. In a previous study, athletics (64/86; 74.4\%) (Nose-Ogura et al. 2019), track (0/4; 0.0\%) (Tenforde et al. 2017), cycling (3/4; 75.0\%) (Nose-Ogura et al. 2019), swimming (7/11;63.6\%) (Nose-Ogura et al. 2019), gymnastics $(7 / 7 ; 100.0 \%)$ (Nose-Ogura et al. 2019) (9/16; 56.2\%) (Tenforde et al. 2017), rhythmic 
236

237

238

239

240

241

242

243

244

245

246

247

248

249

250

251

252

253

254

255

256

257

258

gymnastics $(31 / 35 ; 88.6 \%)$ (Nose-Ogura et al. 2019), and cross-country $(23 / 47 ; 48.9 \%)$

(Tenforde et al. 2017) were in the moderate or high-risk categories. Although there is no clear consensus, it was considered that there were many endurance and aesthetic sports athletes in the middle- and high-risk categories.

In addition, for each scoring category, there was a large proportion (41/116, 35.3\%) with a history of bone stress fractures, particularly in athletics long-distance $(7 / 8 ; 87.8 \%)$. In previous studies, female athletes were at a higher risk of bone stress fractures than male athletes (De Souza et al. 2014a. (De Souza et al. 2014; Nose-Ogura et al. 2019). It has also been reported that the frequency of bone stress fractures among 1616 female Japanese athletes and 537 controls (non-athletes) was $22.6 \%$ for athletes competing at the international level, $23.3 \%$ for athletes competing at the national level, $20.8 \%$ for athletes competing at the local level, $18.8 \%$ for athletes competing at other levels, and 4.3\% for controls (Takamatsu \& Kitawaki 2016). Therefore, the athletes in the present study had a high rate of bone stress fractures. Furthermore, careful consideration should be given to the reason why significantly more athletes were in the moderate-risk category than in the low-risk category in athletics long-distance.

Several limitations must be considered in this study. First, the 1000 athlete exposures could not be calculated. Second, the survey of injuries during sports activities was conducted for one season from April 2018 to March 2019, but medical examinations and anthropometry were conducted from August 2018 to January 2019. Therefore, this was not a prospective study. In the future, prospective research will be needed. Third, the actual LEA, defined as energy intake minus energy expenditure of exercise relative to fat-free mass $<30 \mathrm{kcal} / \mathrm{kg}$ of FFM/d, was not measured in this study. Fourth, BMD was measured on the heel of the right leg using an ultrasonic bone densitometer, and calculated Z-score in this study. BDM from ultrasonic bone 
259 densitometer cannot be used for diagnostic classification and it is not clinically useful for

260 monitoring the effects of therapy (Lewiecki et al. 2006). And a calcaneus ultrasound T-score is

261 commonly higher than a central x-ray absorptiometry T-score and could give the false

262 impression (Lewiecki \& Lane 2008). However, Z-score, which is not used with the WHO

263 classification, rather than T-scores, are preferred for reporting the results for premenopausal

264 women, men under the age of 50 years and children (Lewiecki \& Lane 2008).

265

266 Conclusions

267 suggest that athletes in the moderate and high-risk categories of the Triad may be at increased risk of injury.

\section{Acknowledgements}




\section{References}

284

Arendt EA, Bershadsky B, and Agel J. 2002. Periodicity of noncontact anterior cruciate ligament injuries during the menstrual cycle. $J$ Gend Specif Med 5:19-26.

Barrack MT, Gibbs JC, De Souza MJ, Williams NI, Nichols JF, Rauh MJ, and Nattiv A. 2014. Higher incidence of bone stress injuries with increasing female athlete triad-related risk factors: a prospective multisite study of exercising girls and women. Am J Sports Med 42:949-958. 10.1177/0363546513520295

Beynnon BD, Johnson RJ, Braun S, Sargent M, Bernstein IM, Skelly JM, and Vacek PM. 2006. The relationship between menstrual cycle phase and anterior cruciate ligament injury: a case-control study of recreational alpine skiers. Am J Sports Med 34:757-764. $10.1177 / 0363546505282624$

De Souza MJ, Nattiv A, Joy E, Misra M, Williams NI, Mallinson RJ, Gibbs JC, Olmsted M, Goolsby M, and Matheson G. 2014. 2014 Female Athlete Triad Coalition Consensus Statement on Treatment and Return to Play of the Female Athlete Triad: 1st International Conference held in San Francisco, California, May 2012 and 2nd International Conference held in Indianapolis, Indiana, May 2013. Br J Sports Med 48:289. 10.1136/bjsports-2013-093218

Gibbs JC, Nattiv A, Barrack MT, Williams NI, Rauh MJ, Nichols JF, and De Souza MJ. 2014. Low bone density risk is higher in exercising women with multiple triad risk factors. Med Sci Sports Exerc 46:167-176. 10.1249/MSS.0b013e3182a03b8b

Hewett TE, Myer GD, and Ford KR. 2006. Anterior cruciate ligament injuries in female athletes: Part 1, mechanisms and risk factors. Am J Sports Med 34:299-311. 
306

Hewett TE, Zazulak BT, and Myer GD. 2007. Effects of the menstrual cycle on anterior cruciate ligament injury risk: a systematic review. Am J Sports Med 35:659-668.

\section{$10.1177 / 0363546506295699$}

Junge A, Engebretsen L, Alonso JM, Renström P, Mountjoy M, Aubry M, and Dvorak J. 2008. Injury surveillance in multi-sport events: the International Olympic Committee approach. Br J Sports Med 42:413-421. 10.1136/bjsm.2008.046631

Lewiecki EM, and Lane NE. 2008. Common mistakes in the clinical use of bone mineral density testing. Nat Clin Pract Rheumatol 4:667-674. 10.1038/ncprheum0928

Lewiecki EM, Richmond B, and Miller PD. 2006. Uses and misuses of quantitative ultrasonography in managing osteoporosis. Cleve Clin J Med 73:742-746, 749-752. $10.3949 /$ cjm. 73.8 .742

Mallinson RJ, and De Souza MJ. 2014. Current perspectives on the etiology and manifestation of the "silent" component of the Female Athlete Triad. Int J Womens Health 6:451-467. 10.2147/ijwh.S38603

Mountjoy M, Sundgot-Borgen J, Burke L, Carter S, Constantini N, Lebrun C, Meyer N, Sherman R, Steffen K, Budgett R, and Ljungqvist A. 2014. The IOC consensus statement: beyond the Female Athlete Triad--Relative Energy Deficiency in Sport (RED-S). Br J Sports Med 48:491-497. 10.1136/bjsports-2014-093502

Mountjoy M, Sundgot-Borgen JK, Burke LM, Ackerman KE, Blauwet C, Constantini N, Lebrun C, Lundy B, Melin AK, Meyer NL, Sherman RT, Tenforde AS, Klungland Torstveit M, and Budgett R. 2018. IOC consensus statement on relative energy deficiency in sport (RED-S): 2018 update. Br J Sports Med 52:687-697. 10.1136/bjsports-2018-099193 
328 Nattiv A. 2000. Stress fractures and bone health in track and field athletes. J Sci Med Sport

329

330

331

332

333

334

335

336

337

338

339

340

341

342

343

344

345

346

347

348

349

350 3:268-279. 10.1016/s1440-2440(00)80036-5

Nattiv A, Kennedy G, Barrack MT, Abdelkerim A, Goolsby MA, Arends JC, and Seeger LL. 2013. Correlation of MRI grading of bone stress injuries with clinical risk factors and return to play: a 5-year prospective study in collegiate track and field athletes. $\mathrm{Am} J$ Sports Med 41:1930-1941. 10.1177/0363546513490645

Nose-Ogura S, Yoshino O, Dohi M, Kigawa M, Harada M, Hiraike O, Onda T, Osuga Y, Fujii T, and Saito S. 2019. Risk factors of stress fractures due to the female athlete triad:

Differences in teens and twenties. Scand J Med Sci Sports 29:1501-1510. 10.1111/sms. 13464

Park SK, Stefanyshyn DJ, Ramage B, Hart DA, and Ronsky JL. 2009. Alterations in knee joint laxity during the menstrual cycle in healthy women leads to increases in joint loads during selected athletic movements. Am J Sports Med 37:1169-1177. $10.1177 / 0363546508330146$

Reeder MT, Dick BH, Atkins JK, Pribis AB, and Martinez JM. 1996. Stress fractures. Current concepts of diagnosis and treatment. Sports Med 22:198-212. 10.2165/00007256199622030-00006

Takamatsu K, and Kitawaki J. 2016. Annual report of the Women's Health Care Committee, Japan Society of Obstetrics and Gynecology, 2016. J Obstet Gynaecol Res 42:1419-1438. $10.1111 /$ jog. 13130

Tenforde AS, Carlson JL, Chang A, Sainani KL, Shultz R, Kim JH, Cutti P, Golden NH, and Fredericson M. 2017. Association of the Female Athlete Triad Risk Assessment Stratification to the Development of Bone Stress Injuries in Collegiate Athletes. Am J 
352 Tenforde AS, Sayres LC, McCurdy ML, Sainani KL, and Fredericson M. 2013. Identifying sexspecific risk factors for stress fractures in adolescent runners. Med Sci Sports Exerc 45:1843-1851. 10.1249/MSS.0b013e3182963d75

355
Wojtys EM, Huston LJ, Boynton MD, Spindler KP, and Lindenfeld TN. 2002. The effect of the menstrual cycle on anterior cruciate ligament injuries in women as determined by hormone levels. Am J Sports Med 30:182-188. 10.1177/03635465020300020601

Wojtys EM, Huston LJ, Lindenfeld TN, Hewett TE, and Greenfield ML. 1998. Association between the menstrual cycle and anterior cruciate ligament injuries in female athletes. $\mathrm{Am}$ J Sports Med 26:614-619. 10.1177/03635465980260050301 
362

363

364

365

366

367

368

369

370

371

372

373

374

375

376

377

378

379

380

381

382

383

384

385

\section{Legends}

Figure 1 Percentage of athletes with the female athlete Triad.

A bone mineral density Z-score of $<-1.0$ in the heel is defined as low bone mineral density. The

Triad is defined as energy intake minus energy expenditure of exercise relative to $<30 \mathrm{kcal} / \mathrm{kg}$ of fat-free mass/d, but it is very difficult to calculate energy balance this way during medical examinations. Therefore, the American College of Sports Medicine defines low energy availability in adolescent athletes as a body weight $<85 \%$ of ideal body weight, and for adult athletes in their $20 \mathrm{~s}$, a body mass index $\leq 17.5 \mathrm{~kg} / \mathrm{m}^{2}$. Therefore, these criteria were used in the present study. Body mass index was calculated as body weight $(\mathrm{kg}) / \mathrm{height}\left(\mathrm{m}^{2}\right)$. To calculate ideal body weight, the formula recommended by The Japanese Society for Pediatric Endocrinology was used.

\section{Table 1: Prevalence in the 7 events for 116 athletes assigned to triad risk categories.}

Data presented as n $(\%)$.

${ }^{\mathrm{a}} \mathrm{p}=0.004$ vs. moderate and high-risk category

${ }^{\mathrm{b}} \mathrm{p}=0.004$ vs. low and high-risk category

Table 2: Number of athletes in each event by female athlete triad coalition scoring category.

Data presented as n (\%).

\section{Table 3: Number of injuries by triad risk category.}

Data presented as n (\%).

${ }^{\mathrm{a}} \mathrm{p}=0.01$, Non-injury group with moderate risk (\%) 
$386{ }^{\mathrm{b}} \mathrm{p}=0.01$, Injury group with low risk (\%)

387

388 Table 4: Injury diagnosis by triad risk category.

389 Data presented as n (\%).

390 Only injuries that were diagnosed are listed.

$391{ }^{a} \mathrm{p}=0.023 \mathrm{vs}$. low-risk category for stress fracture

$392 b^{b} p=0.023$ vs. low-risk category for bursitis 


\section{Table $\mathbf{1}$ (on next page)}

Prevalence in the 7 events for 116 athletes assigned to triad risk categories.

Data presented as $n(\%) .{ }^{a} p=0.004$ vs. moderate and high-risk category ${ }^{b} p=0.004$ vs. low and high-risk category 
1 Table 1: Prevalence in the 7 events for 116 athletes assigned to triad risk categories.

\begin{tabular}{lcccc}
\hline Sport & No. of athletes & Low risk & Moderate risk & High risk \\
\hline Swimming & 11 & $11(100.0)^{\mathrm{a}}$ & $0(0.0)$ & $0(0.0)$ \\
Athletics sprint & 19 & $11(57.9)$ & $8(42.1)$ & $0(0.0)$ \\
Athletics long-distance & 8 & $2(25.0)$ & $5(62.5)^{\mathrm{b}}$ & $1(12.5)$ \\
Athletics throwing/jumping & 8 & $7(87.5)$ & $1(12.5)$ & $0(0.0)$ \\
Soccer & 27 & $19(70.4)$ & $5(19.2)$ & $0(0.0)$ \\
Basketball & 26 & $21(80.8)$ & $3(17.6)$ & $0(0.0)$ \\
Volleyball & 17 & $14(82.4)$ & $30(25.9)$ & $1(0.8)$ \\
\hline Total & 116 & $85(73.3)$ & & \\
\hline
\end{tabular}

2 Data presented as $\mathrm{n}(\%)$.

$3{ }^{\mathrm{a}} \mathrm{p}=0.007$ vs. moderate and high-risk category

$4{ }^{b} p=0.007$ vs. low and high-risk category 


\section{Table 2 (on next page)}

Number of athletes in each event by female athlete triad coalition scoring category.

Data presented as $\mathrm{n}(\%)$. 
1 Table 2. Number of athletes in each event by female athlete triad coalition scoring category

\begin{tabular}{|c|c|c|c|c|c|c|c|c|}
\hline Category and risk score & $\begin{array}{c}\text { Swimmin } \\
\mathbf{g} \\
(n=11)\end{array}$ & $\begin{array}{l}\text { Athletic } \\
\text { sprint } \\
(n=19)\end{array}$ & $\begin{array}{l}\text { Athletic long- } \\
\text { distance } \\
(n=8)\end{array}$ & $\begin{array}{c}\text { Athletic } \\
\text { throwing/J } \\
\text { umping } \\
(n=8)\end{array}$ & $\begin{array}{l}\text { Soccer } \\
(n=27)\end{array}$ & $\begin{array}{l}\text { Basketball } \\
\quad(n=26)\end{array}$ & $\begin{array}{l}\text { Volleyball } \\
(n=17)\end{array}$ & $\begin{array}{c}\text { Total } \\
(n=116)\end{array}$ \\
\hline \multicolumn{9}{|l|}{ Low energy availability } \\
\hline High score & $0(0.0)$ & $0(0.0)$ & $0(0.0)$ & $0(0.0)$ & $0(0.0)$ & $0(0.0)$ & $0(0.0)$ & $0(0.0)$ \\
\hline \multicolumn{9}{|l|}{$\begin{array}{l}\text { Body mass index or } \\
\text { ideal body weight }\end{array}$} \\
\hline Low score & $11(9.5)$ & $14(12.1)$ & $7(6.0)$ & $7(6.0)$ & $25(21.6)$ & $25(21.6)$ & $16(13.8)$ & $105(90.5)$ \\
\hline Moderate score & $0(0.0)$ & $3(2.6)$ & $0(0.0)$ & $1(0.9)$ & $1(0.9)$ & $1(0.9)$ & $1(0.9)$ & $7(6.0)$ \\
\hline Moderate score & $0(0.0)$ & $2(1.7)$ & $4(3.4)$ & $1(0.9)$ & $4(3.4)$ & $4(3.4)$ & $2(1.7)$ & $17(14.7)$ \\
\hline High score & $0(0.0)$ & $0(0.0)$ & $1(0.9)$ & $0(0.0)$ & $0(0.0)$ & $1(0.9)$ & $0(0.0)$ & $2(1.7)$ \\
\hline \multicolumn{9}{|l|}{$\begin{array}{l}\text { Oligomenorrhea/ } \\
\text { amenorrhea }\end{array}$} \\
\hline Low score & $11(9.5)$ & $13(11.2)$ & $6(5.2)$ & $7(6.0)$ & $24(20.7)$ & $21(18.1)$ & $16(13.8)$ & $98(84.5)$ \\
\hline Moderate score & $0(0.0)$ & $5(4.3)$ & $1(0.9)$ & $1(0.9)$ & $1(0.9)$ & $2(1.7)$ & $0(0.0)$ & $10(8.6)$ \\
\hline High score & $0(0.0)$ & $1(0.9)$ & $1(0.9)$ & $0(0.0)$ & $2(1.7)$ & $3(2.6)$ & $1(0.9)$ & $8(6.9)$ \\
\hline \multicolumn{9}{|l|}{$\begin{array}{l}\text { Low bone mineral } \\
\text { density }\end{array}$} \\
\hline Low score & $11(9.5)$ & $19(16.4)$ & $8(6.9)$ & $8(6.9)$ & $27(23.3)$ & $26(22.4)$ & $17(14.7)$ & $116(100.0)$ \\
\hline
\end{tabular}




\begin{tabular}{lcccccccc} 
Moderate score & $0(0.0)$ & $0(0.0)$ & $0(0.0)$ & $0(0.0)$ & $0(0.0)$ & $0(0.0)$ & $0(0.0)$ & $0(0.0)$ \\
$\quad$ High score & $0(0.0)$ & $0(0.0)$ & $0(0.0)$ & $0(0.0)$ & $0(0.0)$ & $0(0.0)$ & $0(0.0)$ & $0(0.0)$ \\
\hline $\begin{array}{l}\text { Stress reaction/fracture } \\
\text { Low score }\end{array}$ & $11(9.5)$ & $10(8.6)$ & $1(0.9)$ & $6(5.2)$ & $18(15.5)$ & $20(17.2)$ & $9(7.8)$ & $75(64.7)$ \\
$\quad$ Moderate score & $0(0.0)$ & $8(6.9)$ & $4(3.4)$ & $2(1.7)$ & $9(7.8)$ & $6(5.2)$ & $7(6.0)$ & $36(31.0)$ \\
High score & $0(0.0)$ & $1(0.9)$ & $3(2.6)$ & $0(0.0)$ & $0(0.0)$ & $0(0.0)$ & $1(0.9)$ & $5(4.3)$ \\
\hline
\end{tabular}

Data presented as $\mathrm{n}(\%)$. 


\section{Table 3 (on next page)}

Number of injuries by triad risk category.

Data presented as $n(\%) .{ }^{a} p=0.01$, Non-injury group with moderate risk (\%) ${ }^{b} p=0.01$, Injury group with low risk (\%) 
1 Table 3: Number of injuries by triad risk category.

\begin{tabular}{lcccc}
\hline Kind of sport & \multicolumn{2}{c}{ Injury group ( $\mathbf{n}=\mathbf{4 1 )}$} & Non-injury group (n=75) \\
\hline & Low risk (\%) & Moderate and high risk (\%) & Low risk (\%) & Moderate and high risk (\%) \\
\hline Swimming & $3(7.3)$ & $0(0.0)$ & $8(10.7)$ & $0(0.0)$ \\
Athletics sprint & $0(0.0)$ & $1(2.4)$ & $13(17.3)$ & $5(6.7)$ \\
Athletics long-distance & $0(0.0)$ & $3(7.3)$ & $2(2.7)$ & $3(4.0)$ \\
Athletics throwing/jumping & $2(4.9)$ & $1(2.4)$ & $5(6.7)$ & $0(0.0)$ \\
Soccer & $12(29.3)$ & $6(14.6)$ & $16(10.7)$ & $1(1.3)$ \\
Basketball & $5(12.2)$ & $2(4.9)$ & $10(13.3)$ & $3(4.0)$ \\
Volleyball & $4(9.8)$ & $2(4.9)$ & $62(82.7)^{\mathbf{b}}$ & $1(1.3)$ \\
\hline Total & $25(61.0)$ & $16(39.0)^{a}$ & $13(17.3)$ \\
\hline
\end{tabular}

2 Data presented as n (\%).

3 ap $=0.01$, Non-injury group with moderate risk (\%)

$4{ }^{b} p=0.01$, Injury group with low risk (\%) 


\section{Table 4 (on next page)}

Injury diagnosis by triad risk category.

Data presented as $n(\%)$. Only injuries that were diagnosed are listed. ${ }^{a} p=0.023$ vs. low-risk category for stress fracture ${ }^{b} p=0.023$ vs. low-risk category for bursitis 
1 Table 4: Injury diagnosis by triad risk category.

\begin{tabular}{lcc}
\hline Injury diagnosis & Low risk & Moderate and high risk \\
\hline Concussion & $4(6.2)$ & $1(1.5)$ \\
Fracture & $2(3.1)$ & $0(0.0)$ \\
Stress fracture & $0(0.0)$ & $4(6.2)^{\mathrm{a}}$ \\
Other bone injuries & $0(0.0)$ & $1(1.5)$ \\
Dislocation, subluxation & $5(7.7)$ & $1(1.5)$ \\
Ligamentous rupture & $2(3.1)$ & $0(0.0)$ \\
Sprain & $8(12.3)$ & $6(9.2)$ \\
Lesion of meniscus or cartilage & $3(4.6)$ & $0(0.0)$ \\
Strain / muscle rupture / tear & $4(6.2)$ & $0(0.0)$ \\
Contusion / hematoma/ bruise & $6(9.2)$ & $0(0.0)$ \\
Tendinosis / tendinopathy & $4(6.2)$ & $2(3.1)$ \\
Bursitis & $1(1.5)$ & $4(6.2)^{\mathrm{b}}$ \\
Muscle cramps or spasm & $1(1.5)$ & $1(1.5)$ \\
Nerve injury / spinal cord injury & $1(1.5)$ & $0(0.0)$ \\
Others (nail trouble, heatstroke) & $3(4.6)$ & $1(1.5)$ \\
\hline Total & $44(67.7)$ & $21(32.3)$ \\
\hline
\end{tabular}

2 Data presented as n (\%).

3 Only injuries that occurred are listed.

$4{ }^{a} p=0.014$ vs. low-risk category for stress fracture

5 b $\mathrm{b}=0.014$ vs. low-risk category for bursitis 


\section{Figure 1}

Percentage of athletes with the female athlete Triad.

A bone mineral density Z-score of $<-1.0$ in the heel is defined as low bone mineral density. The Triad is defined as energy intake minus energy expenditure of exercise relative to $<30$ $\mathrm{kcal} / \mathrm{kg}$ of fat-free mass $/ \mathrm{d}$, but it is very difficult to calculate energy balance this way during medical examinations. Therefore, the American College of Sports Medicine defines low energy availability in adolescent athletes as a body weight $<85 \%$ of ideal body weight, and for adult athletes in their $20 \mathrm{~s}, \mathrm{a} b$ ody mass index $\leq 17.5 \mathrm{~kg} / \mathrm{m}^{2}$. Therefore, these criteria were used in the present study. Body mass index was calculated as body weight $(\mathrm{kg}) / \mathrm{height}\left(\mathrm{m}^{2}\right)$. To calculate ideal body weight, the formula recommended by The Japanese Society for Pediatric Endocrinology was used. 


\section{Amenorrhea}

(over 3 months or $<6$ menses in 12 months)

$\mathrm{n}: 116$

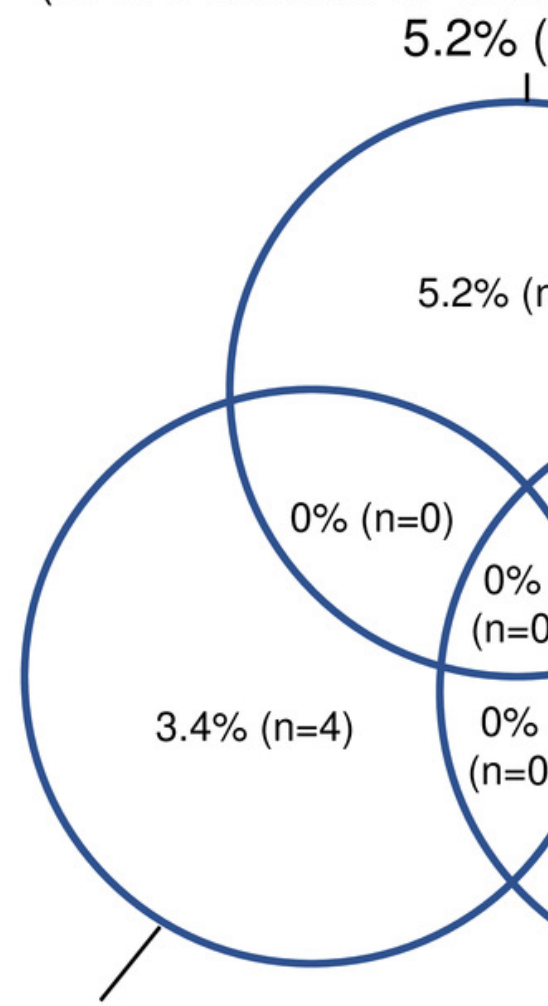

Low energy availability (body mass index: $\leq 17.5$ or ideal body weight $<85 \%)$

$1.7 \%(n=2)$
Low bone mineral density

$(Z$-score:<-1.0)

$0 \%(n=0)$ 